\title{
Estanislao Zeballos y la valorización simbólica de la naturaleza en la conformación del estado nación argentino a fines del siglo XIX. Un estado de la cuestión desde la ecología política
}

\section{FACUNDO IGLESIAS}

Facultad de Humanidades y Ciencias de la Educación, Universidad Nacional de La Plata, Argentina facuidx@gmail.com

\section{RESUMEN}

Este trabajo ofrece un primer avance desde la Ecología Política en el análisis de la construcción discursiva de Estanislao Zeballos al frente del Instituto Geográfico Argentino y el Ministerio de Relaciones Exteriores. Se busca poner en cuestión tanto el desempeño de Zeballos como escritor como también en su función política y científica en contexto con la formación del Estado Nación argentino moderno de fin de siglo XIX, donde se disputaron diferentes concepciones y valorizaciones de la naturaleza en detrimento de otras cosmovisiones y apropiaciones propias de las poblaciones originarias de Pampa-Patagonia.

PALABRAS CLAVE: territorio; geografía; ciencia

Recepción: 18/09/2020 | Evaluación: 06/11/2020 | Aceptación: 27/11/2020 


\section{ABSTRACT}

ESTANISLAO ZEBALLOS AND THE SYMBOLIC VALORIZATION OF NATURE IN THE CONFORMATION OF THE ARGENTINEAN NATION STATE AT THE END OF THE 19TH CENTURY. A STATE OF THE QUESTION FROM THE POLITICAL ECOLOGY

This work offers a first advance from Political Ecology in the analysis of the discursive construction of Estanislao Zeballos at the head of the Argentine Geographic Institute and the Ministry of Foreign Affairs. It seeks to question Zeballos' performance as a writer as well as his political and scientific role in the context of the formation of the modern Argentinean Nation State at the end of the igth century, where different conceptions and valorizations of nature were disputed to the detriment of other cosmovisions and appropriations typical of the original populations of Pampa-Patagonia.

KEYWORDS: territory; geography; science 


\section{RESUMO}

\section{ESTANISLAO ZEBALLOS E A VALORIZAÇÃO SIMBÓLICA DA NATUREZA NA FORMAÇÃO DO ESTADO-NAÇÃO ARGENTINO NO FINAL DO SÉCULO XIX. UM ESTADO DE COISAS DO PONTO DE VISTA DA ECOLOGIA POLÍTICA}

Este trabalho oferece um primeiro avanço da Ecologia Política na análise da construçáo discursiva de Estanislao Zeballos à frente do Instituto Geográfico Argentino e do Ministério dos Negócios Estrangeiros. Procura questionar o desempenho de Zeballos como escritor, bem como o seu papel político e científico no contexto da formação do moderno Estado Nacional Argentino no final do século XIX, onde diferentes concepçôes e valores da natureza eram disputados em detrimento de outras visóes e apropriaçóes mundiais das populaçôes originais de Pampa-Patagónia.

PALAVRAS-CHAVE: território; geografia; ciência 


\section{Introducción}

Un revisionismo científico desde la Ecología Política nos permitirá ampliar el debate y revalorizar ciertos lenguajes y prácticas culturales, por fuera del posicionamiento del paradigma positivista moderno, el cual cimentó la conformación del Estado Nación argentino en la segunda mitad del siglo XIX. El avance progresivo y la destrucción de la frontera no solo sistematizó su accionar en términos étnicos y políticos, sino también en términos ambientales. De este modo se logra ampliar el análisis en el avance sobre la frontera sur no solo como un proyecto político y militar, sino también como un proyecto ecoterritorial.

En efecto, la apropiación de la naturaleza por parte del Estado nacional reflejó una desigualdad en términos simbólicos por sobre aquellos que mantenían diferentes valoraciones respecto de esta, como planteaban los pueblos originarios ${ }^{2}$ que habitaban el actual territorio nacional. Históricamente y a través de los distintos sistemas de explotación, la naturaleza es objeto de una creciente apropiación, destrucción y mercantilización por parte de una elite dirigente. Esta situación ha provocado una valoración de la naturaleza en el imaginario social y científico, categorizándola como mero medio para la generación de riqueza. Sin embargo, la resistencia a esta concepción de uso instrumental de la misma se expresa a través de la confrontación de estos pueblos originarios los cuales luchan, hasta la actualidad, por la reapropiación y conservación de su propia cultura y de sus formas de vida (Delrio et al., 20IO). Lo interesante en esta discusión es plantear que el juego del lenguaje se produce en la rivalidad de las posiciones sociales, contraste que genera nuevas diferencias y estimula la creación de nuevos discursos y juegos simbólicos (Alimonda, 20I5).

Este material pretende enmarcarse en el cruce entre la Ecología Política y la historia institucional de la Geografía, haciendo eje en Zeballos como funcionario y escritor. Esto implica analizar tanto su desempeño como diputado y su papel en estas instituciones geográficas como, al mismo

1 Svampa (2019) enfatiza que la desigualdad de los costos ambientales, la falta de participación y de democracia, el racismo ambiental hacia los pueblos originarios, en fin, la injusticia de género y la deuda ecológica, están en el origen de diversas redes de justicia ambiental.

2 La construcciones y análisis de las concepciones y valoraciones de la naturaleza de las poblaciones originarias están basadas en los relatos y obras de expedicionarios de época como Musters (2007), Guinnard (2008), Mansilla (2018), entre otros. 
tiempo, el desarrollo de sus piezas literarias más relevantes 3 . En síntesis, se pondrá particular atención en la figura de Estanislao Zeballos en tanto responsable de la creación del Instituto Geográfico Argentino (desde ahora IGA) y el Ministerio de Relaciones Exteriores (desde ahora MRE) y como vocero del discurso moderno de progreso. Discurso que, como afirma la historiografía, se objetivó en el accionar geográfico que sirvió para la dominación de las poblaciones originarias (Zusman, 1996; Escolar, I99I; Lois, 1997). A su vez, como también plantean Neiburg y Plotkin (2004), la construcción de un conocimiento social civilizatorio junto con aparición de estas ciencias sociales, fueron parte de procesos fuertemente vinculados al desarrollo de necesidades y demandas del Estado modernizado y burocratizado de fin del siglo XIX y principios del XX.

Creo que el discurso encarnado por Estanislao Zeballos ayudó en gran parte a instalar la desigualdad del capital cultural, la exclusión espacial, la violencia física y simbólica, y la introducción de nuevos códigos y formas de apropiación sobre una naturaleza improductiva, desértica y deshabitada (Corbetta y Ferrás, 2009).

\section{Construcción de poder sociedad-naturaleza}

Históricamente y a través de los distintos sistemas de explotación, la naturaleza ha sido objeto de una creciente apropiación, destrucción y mercantilización. Esta situación ha provocado que haya quedado subsumida, en el imaginario social, a una categoría de mero medio para la generación de riqueza, y esto se ha reflejado en el lenguaje.

A mi forma de ver, y en referencia a estos problemas puntuales, cualquier relación ambiental implicaría relaciones políticas de poder; de la misma forma, toda política conlleva un componente ambiental.

El extractivismo intenta aumentar sus beneficios simbólicos, construyendo valores y poniendo en juego este capital discursivo, social y culturalmente codificado. Tal como dice Bourdieu (I99I) este discurso lleva

3 La conquista de quince mil leguas: estudio sobre la traslacion de la frontera Sud de la república al Rio Negro, dedicado á los gefes y oficiales del ejército expedicionario. (1878); Episodios en los territorios del sur (1879); Descripcion amena de la Republica argentina...: Viaje al pais de los araucanos (1881); Descripción amena de la Republica argentina...: La rejion del trigo (1883); Descripción amena de la República Argentina. A través de las cabañas (1888). 
una marca social, de poder y de valor, respondiendo a la situación en la que se ha producido. El valor de los discursos deviene en la aceptabilidad y la legitimidad de estos en los contextos socio históricos concretos, tanto en las prácticas de los sujetos como en la negociación de los mismos discursos, es decir, estas relaciones se ven determinadas por prácticas de poder que se enmarcan en su posición estratégica en el espacio social.

El poder del discurso como poder simbólico demuestra la capacidad que tienen diferentes agentes en el intercambio, y en la forma de establecer criterios de validación que le sean favorables a sus propias prácticas extractivistas. Estos discursos y los diferentes habitus se terminan naturalizando y aceptando en el sentido común, legitimando la construcción de poderes desiguales y arbitrarios. Sin embargo, la resistencia a esta concepción de uso instrumental de la naturaleza se expresa a través de otros colectivos sociales organizados, quienes luchan por la reapropiación y conservación de la naturaleza, su propia cultura y de sus formas de vida.

\section{Ecología Política: territorio y naturaleza}

La Ecología Política es un encuentro de diálogo multidisciplinar. Una corriente epistemológica que nos permite entender las relaciones de poder que existen en el intercambio sociedad-naturaleza. Esta línea teórica ofrece una salida crítica y analítica en diferentes escalas territoriales, como por ejemplo la conformación geográfica del Estado Nación argentino.

En principio, para Martínez Alier (2008), los conflictos de distribución ecológica responden a la manera en que son distribuidos los costos y beneficios de ciertos usos de los recursos naturales, por formas ya establecidas o a establecer para su explotación, básicamente en una desigual distribución de poder. De la misma forma, para este autor existen diferentes discursos de valoración social respecto de la naturaleza: algunos en relación con un sentido monetario o material y otros que se concentran en valorar lo simbólico o sentimental con capacidad de protegerla.

De la misma forma Lipietz (2002) plantea que las relaciones entre los humanos y la naturaleza son mediatizadas por relaciones de poder. Es decir, que los beneficios que las actividades extractivistas rinden en lo nacional, se minimizan discursivamente junto con los efectos ambientales de depredación. Para Alimonda (2015) los beneficios y costos se 
reparten de forma desigual de acuerdo con los sectores sociales que toman el poder en esos proyectos conformando una condición equivalente a la dominación colonial, y a la colinealidad misma de la naturaleza. Desde aquí es que se busca criticar presupuestos civilizatorios de la modernidad y del desarrollo. En este trabajo pretendo poner en duda la conceptualización de progreso de la modernidad eurocéntrica. En búsqueda de una perspectiva histórica desde la Ecología Política junto con la historia ambiental que proponga una discusión de los procesos de conquista y avance sobre poblaciones originarias y su incorporación a los proyectos nacionales modernos.

Desde mi punto de vista entonces la Ecología Política nos permite analizar la construcción y sistematización social de la naturaleza tanto en términos materiales como en su construcción imaginaria y simbólica. Buscando estudiar de qué forma la ciencia, como parte de la sociedad, imagina e inventa las nociones de naturaleza. Para Alimonda (20I2) el marxismo y la ciencia del siglo XIX ya demostraban que el progreso de la ciencia y la tecnología iban a domesticar la naturaleza. Estas corrientes del saber del XIX minimizan e intentan deslegitimar otros saberes de la naturaleza mediante un saber científico de progreso propio de la modernidad.

El proyecto económico de Argentina como proveedora de materias primas al mercado internacional, implicó un ejercicio de biopoder sobre la naturaleza como por sobre los espacios físicos, geográficos y hasta los propios cuerpos humanos. La biopolítica como mecanismo para regular la relación entre el territorio y las personas que lo habitan fue parte de los discursos modernos/coloniales que producen no solo territorialidades, sino también "naturalezas" que luego son colonizadas (Alimonda, 20I2). En consecuencia, el impacto ambiental, social y cultural observable en la continuidad del desarrollo nacional fue apoyado por el avance histórico sobre las poblaciones originarias de fines del siglo XIX (Nagy, 2008).

De esta forma, el conflicto por la tierra no solo se da en términos abstractos, es decir, como un bien disponible para el mercado, sino que también es un conflicto espacial; esto implica que el espacio geográfico está dotado de significaciones en la densidad de la sociedad y de los grupos humanos que allí actúan. Tal como lo plantea Medici (20I0) la tierra es considerada un factor de producción en donde existe un dominio estatal sobre ella y sobre sus frutos. Para Alimonda (2015) estas luchas son ambientales y ecoterritoriales en tanto se refieren a la defensa del terri- 
torio y a espacios marcados por la creación y continuidad de relaciones sociales y simbólicas entre sociedades y naturalezas localizadas. La expansión de la frontera sur a la apertura agroexportadora y al mercado económico internacional funcionó como mecanismo de ocupación (Zusman, 2000; Donghi y Hora, 2005; Alimonda y Ferguson, 2004).

A fin de cuentas, existen marcas y huellas cristalizadas en el aparato del Estado Nación, marcas de reorganización del mundo rural, del territorio, y del componente social, en la propia Conquista del Desierto, representadas por ejemplo en las grandes propiedades de producción latifundista. Encontramos en este avance sobre la frontera un proyecto que no se limitaba solo a satisfacer la producción agrícola sino también a la reorganización y reconversión del territorio de las comunidades a espacios sin identidad. En este caso, el Estado se legitima y mantiene esa colinealidad de la naturaleza como eje de la incorporación de Argentina al mercado mundial (Alimonda, 20I5). Desde la mirada de Alimonda (20I2) y Said (1990) la búsqueda de control territorial por parte del Estado Nacional (y la apropiación de tierras) se completó mediante la instauración de un orden social tanto con la eliminación de las poblaciones originarias como en la formación de instituciones que brindaron sustento para la consolidación del aparato político imaginado. A fin de cuentas, observamos un proyecto de modernidad, en búsqueda de incorporar a aquella sociedad que no se halla sujeta a los discursos de dominación y de desarrollo, mediante la creación, en este caso, de instituciones geográficas. Por otro lado, Penhos (2016) plantea que la construcción de este espacio geográfico puede entenderse no como un ajuste pasivo y orgánico a un programa político, científico e ideológico de Estado Nación, tal como se viene planteando, sino más bien puede interpretarse como un conjunto de intervenciones, desde sus propios lenguajes, recursos y tradiciones, a la trama histórico-cultural de fines del siglo XIX.

Por lo tanto, podemos plantear que existe un desierto ${ }^{4} \mathrm{y}$ una naturaleza excesiva que es analizada y construida por exploradores y científicos, para luego ser sistematizada y catalogada, obteniendo información necesaria

4 La discusión historiográfica sobre el concepto de desierto es de larga data (Zusman, 1996; Torre, 2006) En esta pesquisa adoptamos la definición de Hayes (2011) el cual sostiene que el desierto se construye a través de la mirada y la lógica expedicionaria de personajes de la época, encargados de recorrer y de darle un sentido moderno al territorio en búsqueda del proyecto de Nación argentino. 
para su control. Esta naturaleza deja de ser un elemento a contemplar, tal como se la entendía en siglos anteriores para pasar a ser un medio necesario para el progreso. Podemos decir que primero se conquista mediante el conocimiento ordinario y luego es dominada por el saber científico institucionalizado (Corbetta y Ferrás, 2009). A fin de cuentas y como relata Gudynas (1999) es imprescindible desentramar los misterios que esconde mediante una observación empírica y racional.

\section{Estanislao Zeballos y la naturaleza}

Vida y obra de Estanislao Zeballos

En los intersticios del recambio generacional que producirían los hombres nacidos al calor del pacto constitucional de 1853, aparecería un excelente laboratorio para explorar. Es aquí donde se detecta la figura de Estanislao Severo Zeballos. Un carácter de época con capacidad exploratoria y una experiencia multifacética convirtió a Zeballos en un personaje fundamental en la acción política de su generación, desempeñando un papel relevante en el devenir de su vida y en diferentes momentos de la sociedad, principalmente en sus primeros cuarenta años de vida (I854-I894).

Estanislao Severo Zeballos nació en Rosario de Santa Fe el 27 de julio de I854. En I878 editó dos ediciones de La conquista de las I5.00o leguas su obra maestra, fundó del IGA (I879) y en I880 fue elegido diputado por la Capital Federal. En el año I88I apareció el primer tomo de su Descripción amena de la República Argentina, con el título de Viaje al pais de los araucanos, y en $\mathrm{I} 883$ el segundo, Viaje a la región del trigo. Un año más tarde fue reelegido diputado nacional, esta vez por Santa Fe, y publicó Callvucurá y la dinastía de los Piedra, al que siguió Painé o la dinastía de los Zorros (I886). En I888 publica Relmu y la reina de los Pinares y Viaje a través de las cabañas, tercer tomo de la Descripción amena. Entre i884 y I894 presidió la Sociedad Rural Argentina. Tres veces Zeballos ocupó el MRE, durante las presidencias de Juárez Celman (I889-1890), Pellegrini (I89I-I892) y Figueroa Alcorta (I906-I908). A mediados de I889 tenía treinta y cinco años, era diputado por la Capital y ya había sido presidente de la Cámara (Ferrari, 2002).

Desde la creación del Estado central, Zeballos mantuvo una capacidad para observar los problemas del momento desde la espacialidad de las relaciones políticas. Esto le permitió modificar las escalas de análisis y 
resolución de los problemas ampliando un análisis de lo local y provincial al plano nacional. Es decir, y tal como plantea Bonaudo (20II) detrás del impulso del núcleo sólido pero mermado de la Generación del I8375, comenzaban la emergencia de nuevos liderazgos, al tiempo que se gestaba ese lento recambio generacional que arrancaría a dejar sus huellas en la dinámica política de los años I870 y terminaría proyectando a algunos de sus referentes hacia las primeras décadas del siglo XX.

\section{Estanislao Zeballos: obra y naturaleza}

Para Alimonda (2012) aparece entonces un proceso de valorización económica y puesta en valor de los territorios en la obra de Estanislao Zeballos. Como se dijo anteriormente, se completó desde final del siglo XIX a principios del XX un proceso de conquista y ocupación colonial de la naturaleza, transformándola en tierra. De esta forma, se desarticuló el equilibrio social constituido durante siglos y se desvalorizó el sentido de identidad de las poblaciones originarias, como también sus propios imaginarios sociales y espaciales.

Las clases dominantes se establecen como interlocutores válidos en búsqueda del potencial modernizador. En fin, tal como relatan algunos autores (Alimonda y Ferguson, 2004) se produce una destrucción de los pueblos nativos en función de crear un mejor uso de su territorio. Se trata, como plantean Delrio et al. (2010), de un genocidio étnico cultural como fundamento de una reapropiación política de la naturaleza. Personajes como Zeballos hacen su aporte a la demanda de un saber científico para aquello que se consideraba atrasado y disponible al progreso. Estanislao Zeballos, entonces, se constituye como uno de los ideólogos ${ }^{6}$ de la conquista del desierto ya que, junto a otros pensadores de la época, diseñaron una mirada del territorio y de la geografía

5 La Generación del '37 fue un grupo de intelectuales argentinos nacidos en torno a la Revolución de Mayo y a la Independencia. En general, se caracterizaron por adherirse a los principios del Romanticismo, sobre todo al francés y los textos ingleses y alemanes traducidos en París.

6 En 1878, Estanislao Zeballos, en un tiempo récord, escribe, a pedido del general Julio Argentino Roca (ministro de guerra), "La conquista de las 15.000 leguas". Esta obra sería presentada para convencer al Congreso de la Nación Argentina, como un documento propagandístico, un manual de campaña para los mariscales que al poco tiempo llevarían a cabo la llamada conquista del desierto. La virtud de esta obra era dejar plasmado el 
relevante en el discurso del 80 en busca de finalizar las tareas coloniales inconclusas (Alimonda y Ferguson, 2004). Autores como, Viñas (I982) y Sarasola (20I2) sostienen que se iba a repetir un avance sobre las poblaciones originarias de Pampa-Patagonia, catalogada como la última fase o fase superior de la conquista española iniciada cinco siglos atrás, cimentada en concepciones como las de genocidio y desaparecidos?.

Para autoras como Torre (2006) esta expedición civilizatoria no puede estar categorizada como genocidio ya que lo que sucedió fue un sometimiento más que la eliminación de una etnia, por lo que es mejor hablar de "exterminio" debido a que esta supuesta integración civilizatoria implicó una desintegración de las matrices socioculturales de las poblaciones originarias de este periodo. De la misma forma, nos plantea que tampoco podemos hablar de "desaparecidos" ya que en este proceso el sometimiento y "exterminio" no fue de forma clandestina, sino a la vista de todos.

Por lo pronto Díez (20II) sostiene que desde la obra La Conquista de las 15.000 leguas, publicada en I878, Zeballos demuestra el impulso de la ciencia antropométrica. Disciplina que inició sus pasos en el siglo XIX, y no duda en hacer una contribución relevante en el avance y apropiación de los lugares barbarizados más allá de la frontera sur. A la vez, esta obra de Zeballos es una propuesta que no solo aporta al espíritu de la expedición y al plan del General Roca (I843-I9I4), sino también a las finanzas del ejército, a los procedimientos científicos, a los usos de la lengua araucana, y hasta a una futura pieza literaria (Torre, 2006).

La naturaleza se convierte para Zeballos en un excelente laboratorio para explorar y nutrir a la lógica individualista racional-científica y productivista de la sociedad capitalista dominante (Anzoátegui, 20I2). Sujetos como Zeballos fueron poseedores de un saber geográfico e institucionalizado que los catapultaba para construir la geografía del momento. A fin de cuentas para Zusman y Minvielle (1995) se logró sistematizar y recopilar información necesaria para la producción de una geografía situada.

pensamiento hegemónico de toda la generación que planeó la expulsión y el exterminio de los pueblos originarios que habitaban al sur del río Salado.

7 Viñas realiza una crítica revisionista de La Conquista del Desierto desde conceptos contextualizados y comparados a la Dictadura Cívico-Militar de Argentina (1976-1983). 
En contraposición, para las poblaciones originarias estos mismos espacios son vividos y humanizados intensamente, saturados de historia y significación local, como lugares donde plantas, animales, seres vivos, y accidentes geográficos tienen nombres, usos, funciones simbólicas, historias; son lugares en formación indígena de conocimiento. Existió entonces un contundente proceso de apropiación privada de los recursos y del territorio, donde se modifica la cosmovisión comunitaria, el fuerte lazo con el ciclo natural, la tradicional relación comunal que los pueblos originarios tenían con la tierra, y la destrucción de su base social de sustentación (Galafassi, 2009).

\section{La naturaleza y las instituciones geográficas}

Para la Generación del 37 -con figuras como Domingo F. Sarmiento (I8III888), Juan B. Alberdi (I810-I884), entre otros intelectuales contemporáneos ${ }^{8}$ - las perspectivas de desarrollo futuro de Argentina se vinculaba a las condiciones favorables que abría el avance del capitalismo industrial en Europa. En gran medida, lo que se intentaba justamente era suprimir esa alianza no mediada entre la tierra y los hombres de la tierra, creando oposiciones que descalificaran todo aquello que no poseía la distancia necesaria entre tierra y cultura de la tierra. Es decir, civilizar es romper la alianza, suprimir el desierto y mediar la relación con el laboreo de la misma y la industrialización (Corbetta y Ferrás, 2009).

Como vemos, aquello que fue romantizado y fundamentado por la generación del 37 va a ser concretado por la generación de I880, en donde Zeballos ocupo un papel preponderante. De manera tal que podemos pensar que existe una continuación en la proyección de Nación que comenzó con la generación del 37 y la penetración de la modernidad y el deseo de un Estado nacional (Corbetta y Ferrás, 2009). Hay un consenso en la historiografía en aceptar que el proyecto de la generación del 80 se apoyó y se forjó bajo tres pilares fundamentales: la pampa, el desierto, y el espacio habitable y productivo. Para Castro y

8 Aparte de los ya citados, encontramos dentro de la generación del '37 a personajes relevantes como Esteban Echeverría, Vicente Fidel López, Juan María Gutiérrez, Miguel Cané (padre), José Mármol, Félix Frías, Carlos Tejedor, Luis Domínguez, Marco Avellaneda, Antonino Aberastain y Marcos Paz. 
Zusman (2009) la naturaleza de los del 80 es una materialidad útil para el progreso del hombre, mejorada de la mano de la ciencia, la técnica y la función de las instituciones geográficas. A fin de cuentas, aparece un reconocimiento geográfico, dando formación nacional a la Argentina en búsqueda de un mercado unificado de inserción en la división internacional del trabajo (Zusman y Minvielle, 1995). Con la consolidación del Estado Nación y la apropiación excluyente y exclusiva de un campo y un ámbito geográfico, la producción de conocimiento queda supeditada a los deseos de Nación. Tanto el IGA, fundado por Zeballos el 6 de febrero de 1879 (Zusman, 1996; Babini y Montserrat, 1949), como la MRE (designado en I889 ministro de Relaciones Exteriores) tenían dentro de sus objetivos la exploración, descripción y demarcación de los territorios del país produciendo una Geografía Argentina9. De la misma forma, el IGA y el MRE promocionaron el conocimiento territorial y la incorporación de nuevos espacios al mercado productivo nacional e internacional. Se produjo un desarrollo del conocimiento con viajes, expediciones, conferencias, publicaciones y boletines con artículos de las investigaciones sobre el territorio y sus habitantes, que caracterizaban y daban cuenta del avance de la ciencia geográfica (Curto et al., 2008).

Como refiere Mazzitelli Mastricchio (2008) la decisión política de incorporar esos territorios implicaba ponerlos a producir y, para ello, era necesario desarticular cualquier otra forma de producción. En este proceso hubo un reconocimiento del espacio a ser dominado mediante las exploraciones; una recopilación de información referente a las condiciones físicas y las potencialidades económicas del espacio y una sistematización del conocimiento obtenido en las actividades antes descritas con el objetivo de la valorización económica. Para Lois (1997) el Estado contribuyó a la promoción de la Sociedad Geográfica abocada profesionalmente a la construcción cartográfica oficial de la Nación y del conocimiento del patrimonio natural necesario para esta valoración y planificación de los recursos. Es un momento en el que la relación entre imaginarios geográficos hegemónicos de Nación, e imaginarios geográficos situados negocian y resisten a los primeros como parte de

9 Para Zusman, (2000) el desierto se completa con civilización y progreso de la mano de la Geografía, una disciplina clave para el proyecto político territorial de la formación del Estado Argentino. 
la geografía material del momento (Maldonado et al., 2015). El reflejo de este cambio de postura cobró forma con la aparición de las primeras instituciones geográficas oficiales en el país. Para Días (Sin fecha) existe una estrecha relación entre las políticas de expansión territorial y el surgimiento de dos instituciones geográficas relevantes: el IGA (cuya fundación coincide temporalmente con la campaña de Roca de 1879) y MRE (gestionado a la luz de conflictos fronterizos con Chile). Las Sociedades Geográficas en la promoción del conocimiento territorial formaron parte de la incorporación de nuevos espacios al mercado productivo, acompañada por la preocupación por definir los límites con los países vecinos. La ocupación de los territorios sometidos a lógicas de organización indígena y el establecimiento de las fronteras internacionales son entonces dos caras del mismo proceso: la formación del territorio argentino (Zusman y Minvielle, 1995).

Tal como demuestra la bibliografía, la obra de Zeballos tuvo un papel preponderante en la construcción y consolidación de Estado nacional: dicho de otra manera, ya sea como funcionario público al frente de instituciones claves para la conformación de un discurso geográfico -como lo fueron el MRE y el IGA- (Zusman y Minvielle, 1995) o como escritor de obras literarias que instalaron un imaginario sobre el espacio geográfico. La figura de Zeballos es clave para entender la valorización de la naturaleza y la construcción de una geografía nacional (Viña, 1982; Torre, 2006). No obstante, los estudios están enmarcados desde la historia territorial o desde un análisis discursivo; por lo que este trabajo pretende analizar desde de la Ecología Política las prácticas de Zeballos en conjunto, lo que llevó a la profundización y al fortalecimiento de un discurso de valorización de la naturaleza en detrimento de otro.

\section{Consideraciones finales}

Esta primera aproximación desde la Ecología Política al Zeballos fundador del IGA y Ministro de Relaciones Exteriores nos muestra que su accionar durante la década de 1880 se vinculó con momentos claves como la Conquista del Desierto, poniendo en discusión la relación de la sociedad con la naturaleza. Principalmente, su papel en ese Estado en construcción buscaba consolidar y construir una valorización de la naturaleza que justifique el avance sobre el territorio nacional, ya simbó- 
licamente imaginado con anterioridad. El desempeño político e intelectual de este personaje permitió afianzar su presencia argentina frente a otros Estados o poderes y potenciar el modelo de desarrollo dominante avanzando sobre la frontera sur. A fin de cuentas, la naturaleza se fue configurando y valorizando dentro del discurso cientificista moderno la de las instituciones y organismos geográficos de fin del siglo XIX desestimando otras cosmovisiones y vinculaciones territoriales de las poblaciones que habitaban. La conquista de esta naturaleza fue una de los tantos mecanismos utilizados por el Estado Nación argentino para consolidarse y configurarse como territorio nacional. 


\section{Referencias bibliográficas}

Alimonda, H. y Ferguson, J. (2004). La producción del desierto. Las imágenes de la campaña del Ejército Argentino contra los indios, I879. Revista chilena de antropología visual. $\mathrm{N}^{\circ}$, pp. I-28.

Alimonda, H. (2012). Una introducción a la Ecología Política latinoamericana (pasando por la historia ambiental), Rel CoLCA, Universidad Nacional de General Sarmiento, Argentina.

Alimonda, H. (2015). Ecología política latino-americana e pensamento crítico: as vanguardas enraizadas, Desenvolvimento e meio ambiente, $\mathrm{N}^{\circ} 35$. [En línea] Recuperado de: https://revistas.ufpr.br/made/article/view/44557/27092

Anzoátegui, M. (2012). El intelectual, el desierto, el 'otro': Un análisis de Viaje al País de los Araucanos de Estanislao Zeballos, VII Jornadas de Sociología de la UNLP s al 7 de diciembre de 2012 La Plata, Argentina. Argentina en el escenario latinoamericano actual: Debates desde las ciencias sociales, Universidad Nacional de La Plata. [En línea] Recuperado de: http://www.memoria.fahce. unlp.edu.ar/trab eventos/ev.I679/ev.I679.pdf

Bonaudo, M. (201I). Estanislao Zeballos: el hombre de acción política que no se haría jamás un profesional, Fernández, S. \& Navarro, F. (coord.) Scribere est agere: Estanislao Zeballos en la vorágine de la modernidad argentina. Rosario: Quinta Pata \& Camino Ediciones.

Babini, J. y Montserrat, M. (I949). La sociedad científica argentina, Svampa, M. (comp), (2006) Historia de la ciencia argentina, CDMX: Fondo de Cultura económica.

Bourdieu, P. (I99I). Language and symbolic power, Boston: Harvard University Press.

Castro, H. y Zusman, P. (2009). Naturaleza y Cultura: ¿dualismo o hibridación? Una exploración por los estudios sobre riesgo y paisaje desde la Geografía, Investigaciones geográficas, N 70 , pp. I35-I53. [En línea] Recuperado de: http://www.scielo.org.mx/scielo.php?script=sci arttext\&pid=SoI88-46II20090003000IO

Corbetta, S. y Ferrás, G. (2009). Del "exceso" de naturaleza a la representación del desierto, Memoria del 53 Congreso Internacional de Americanistas. Los pueblos americanos: cambios y continuidades. La construcción de lo propio en un mundo globalizado. CDMX.

Curto, S. I.; Jauregui, G. B.; Escuela, M. B.; Lascano, M. E.; Pena, H. O. (2008). La fundación de GÆA Sociedad Argentina de Estudios 
Geográficos-1922, Boletín de GEA, N²6, pp. I-49. [En línea] Recuperado de: http://gaea.org.ar/fundacion.pdf

Delrio, W.; Lenton, D.; Musante, M.; Nagy, M.; Papazian, A.; Pérez, P. (2010). Del silencio al ruido en la Historia. Prácticas genocidas y Pueblos Originarios en Argentina, III Seminario Internacional Políticas de la Memoria "Recordando a Walter Benjamin: Justicia, Historia y Verdad. Escrituras de la Memoria", Buenos Aires, 28, 29. [En línea] Recuperado de: http://www.educacionsantacruz.gov. ar/images/EIB/bibliografia/BIB DELRIO LENTON MUSANTE Y OTROS GENOCIDIO IND\%C3\%8DGENA.pdf

Dias, R. J. (Sin fecha) Cartografía, estado y soberanía. Representaciones visuales del proceso de consolidación del Estado nacional argentino durante la campaña del desierto (I878-I885).

Díez, B. S. (20II). La Trilogía de Estanislao Zeballos, historia de una apropiación hegemónica, IV Seminario Internacional Politicas De La Memoria, Centro Cultural de la Memoria Haroldo Conti, Mesa N6. [En línea] Recuperado de: http://conti.derhuman.jus.gov.ar/20II/Io/mesa 6/ diez mesa 6.pdf

Donghi, T. H.; Hora, R. (2005). Una nación para el desierto argentino, Buenos Aires: Prometeo libros.

Escolar, M (1994). Elementos históricos para una teoría de la diferenciación e integración territorial: geografía política del estado-nación moderno, Ciccolella P.; Laurelli, E.; Rofman, A.; Yanes, L. Integración latinoamericana y territorio: transformaciones socio-económicas, politicas y ambientales en el marco de las politicas de ajuste, Buenos Aires: CEUR.

Ferrari, G. (2002). Estanislao S. Zeballos, Los diplomáticos, N9, pp. 6-26. [En línea] Recuperado de: http://www.cari.org.ar/pdf/diplomaticosog.pdf

Galafassi, G. (2009). La segunda conquista. Saqueo de recursos naturales y territorio y la resistencia de los pueblos originarios en la Patagonia argentina, Futuro indigeno. La sfidadelle Americhe. Educazioneall'economia dei popoli, Roma, Italia, Jaca Book, pp. II9-I30. [En línea] Recuperado de: http:// theomai.unq.edu.ar/Art\%20Galafa La segunda conquistai .pdf

Gudynas, E. (I999). Concepciones de la naturaleza y desarrollo en América Latina, Persona y Sociedad, Vol. I3, N I, pp. IOI-I25. [En línea] Recuperado de: https://flacsoandes.edu.ec/web/imagesFTP/I2671I7299. GudynasConcepcionesNaturalezaPSClog.pdf

Guinnard, A. (2008). Tres años de esclavitud entre los patagones. Stockcero, Inc. 
Hayes, I. M. (20II). Reseña del libro de Claudia Torre. El otro desierto de la Nación Argentina, antología narrativa expedicionaria, Cuadernos de H Ideas, Vol. 5, N5. [En línea] Recuperado de: http://sedici.unlp.edu.ar/bitstream/ handle/Iog15/33222/Documento completo.pdf?sequence $=\mathrm{I}$

Lipietz, A. (2002). A ecologia política, solução para a crise da instância política?, Conferencia CLACSO Democracia sustentàveis? Roteiros para a Ecologia Politica latino-americana na mudança do século, Rio de Janeiro, 23 nov 200o. Traduit par A.M. Galano en: Alimonda (ed) Ecología politica. Naturaleza, sociedad, y utopia, Buenos Aires: CLACSO. [En línea] Recuperado de: http://lipietz.net/IMG/article PDF/article 296.pdf

Lois, C. M. (1997). Representación cartográfica y territorio en la constitución del Estado Nación argentino, Territorios en redefinición. Lugar y mundo en América Latina, N6, pp. I-6. [En línea] Recuperado de: http:// observatoriogeograficoamericalatina.org.mx/egal6/Geografiasocioeconomica/ Geografiapolitica/2I.pdf

Maldonado, J. R.; Mora, J. T.; Rodríguez, E. C.; Gómez, C. L. (2015). Patagonia, territorio de los otros: consideraciones geográfico-políticas en la construcción de la nación Argentina, Revista Geográfica Venezolana, Vol. 56, N², pp. 269-290. [En línea] Recuperado de: https://www.redalyc.org/ $\mathrm{pdf} / 3477 / 347743079007 . \mathrm{pdf}$

Mansilla, L. V. (2018). Una excursión a los indios ranqueles. Buenos Aires: Penguin Clásicos.

Martínez Alier, J. (2008). Conflictos Ecológicos y Lenguajes de Valoración: las relaciones entre la economía ecológica y la ecología política, Papeles, $\mathrm{N}^{\circ}$ I03, pp. II-27. [En línea] Recuperado de: http://nomadas.ourproject.org/wpcontent/uploads/20Io/o8/Conflictos ecologicos JI- MARTINEZ ALIERI. pdf

Mazzitelli Mastricchio M. (2008). La cartografía militar en la Argentina: Hacia la especialización topográfica (I865-I9I2), Boletín del Centro Argentino de Topografía, Buenos Aires, $\mathrm{N}^{\circ} 44$.

Medici, A. M. (20I0) El nuevo constitucionalismo latinoamericano y el giro decolonial: Bolivia y Ecuador, Revista Derecho y Ciencias Sociales, $\mathrm{No}_{3}$, pp. 3-23. [En línea] Recuperado de: http://sedici.unlp.edu.ar/bitstream/ handle/IogI5/I5244/all-ooor.pdf?sequence=I

Musters, G. Ch. (2007). Vida entre los patagones. Un año de excursiones por tierras no frecuentadas entre el estrecho de Magallanes hasta el Río Negro, Buenos Aires: Continente. 
Nagy, M. (2008). Los pueblos originarios y las consecuencias de la Conquista del desierto (I878-I885), Perspectivas desde un estado de la cuestión, Fichas del seminario "Introducción a los derechos humanos", Facultad de Filosofía y Letras. Buenos Aires: UBA. [En línea] Recuperado de: http://www.elortiba. org/old/pdf/Nagy-Sometidos.pdf

Neiburg, F. G.; Plotkin, M. B. (2004). Intelectuales y expertos, Buenos Aires: Paidós.

Penhos, M. (2016). Las fotografías del álbum de Encina, Moreno y Cía, Huellas, $\mathrm{N}^{\circ}$ 9. [En línea] Recuperado de: https://bdigital.uncu.edu.ar/ objetos digitales/8707/o7-penhos-huellas9-2016.pdf

Said, E. (I990). La geografía imaginaria y sus representaciones: orientalizar lo oriental, Orientalismo, Ediciones Literarias, pp. 74-Ioo

Sarasola, C. M. (2012). Argentina de los caciques, Buenos Aires: Editorial del Nuevo Extremo

Svampa, M. (2019). Alcances del giro ecoterritorial, Las fronteras del neoextractivismo en América Latina. Conflictos socioambientales, giro ecoterritorial y nuevas dependencias, Alemania: Calas.

Torre, C. (2006). Estanislao Zeballos y el relato de la araucania, Batticuore, G.; El Jaber, L.; Laera, A. (comps.) Fronteras escritas, Rosario: Beatriz Viterbo.

Vińas, D. (1982). Indios, ejército y frontera, México: Siglo Veintiuno.

Zeballos, E. S. (1878). La conquista de quince mil leguas: estudio sobre la traslacion de la frontera Sud de la república al Rio Negro, dedicado á los gefes y oficiales del ejército expedicionario, Buenos Aires: La Prensa.

Zeballos, E. S. (I88I). Descripcion amena de la Republica argentina: Viaje al pais de los araucanos (Vol. I), Buenos Aires: Peuser.

Zeballos, E. S. (1883). Descripcion amena de la Republica argentina: La rejion del trigo (Vol. 2), Buenos Aires: Peuser.

Zeballos, E. S. (1888). Descripción amena de la República Argentina. A través de las cabañas. (Vol. 3), Buenos Aires: Peuser.

Zeballos, E. S. (2004). Episodios en los territorios del sur, I879, Buenos Aires: Peuser.

Zusman, P.; Minvielle, S. (I995). Sociedades Geográficas y delimitación del territorio en la construcción del Estado-Nación argentino, $V$ Encuentro de Geógrafos de América Latina. [En línea] Recuperado de: https://www. sociedad-estado.com.ar/wp-content/uploads/20II/og/I23.pdf

Zusman, P. (I996). Sociedades Geográficas na promoção do saber ao respeito do território Estratégias políticas e acadêmicas das instituiçóes geográficas 
na Argentina (1879-1942) e no Brasil (1838-1945), disertación de maestría,

Programa de Posgraduación en Integración de América Latina, Universidad de San Pablo.

Zusman, P. (200o). Desierto, Civilización, Progreso: La Geografía del Gran Chaco y el proyecto político territorial de la formación del Estado Argentino, Eria: Revista cuatrimestral de geografia, N 5I, pp. 60-68. 